\title{
INFLUENCE OF TIDAL INLET DEPTH ON WATER LEVEL RESPONSE AND SALINITY INTRUSION IN A LAGOON
}

\author{
Kazuya WATANABE ${ }^{1}$ and Hitoshi TANAKA ${ }^{2}$
}

\begin{abstract}
The Nagatsura-ura Lagoon in Miyagi Prefecture, Japan is a semi-enclosed water area that has been used for aquaculture of oyster for these forty years. Recently, however, death of oysters has frequently occurred due to anoxic water near the bottom, and is a big concern among stakeholders. The Nagatsura-ura Lagoon and Oppa Bay are connected by shallow tidal inlet, and its water depth greatly affects hydrodynamics and water environment in the lagoon. In this study, time variation of water level in the lagoon in response to tidal variation is investigated through spectral analysis to quantify the role of water depth in the hydrodynamic process. Furthermore, the relationship between the inlet water depth and the salinity concentration intruding into the lagoon is examined through 3-D numerical simulation.

Keywords: Nagatsura-ura Lagoon, water level variation, 3D numerical simulation, spectral analysis, salinity intrusions
\end{abstract}

\section{INTRODUCTION}

When water is polluted in a semi-closed water area, it is very difficult to improve the water quality. The Nagatsura-ura Lagoon in Miyagi Prefecture, Japan is a semi-enclosed water area that has been used for oyster firming for these forty years. Recently, however, death of oysters has frequently occurred due to anoxic water appears near the bottom, and is a big concern among stakeholders. Due to this reason, there have been investigations how to improve the water quality in this lagoon area. Effectiveness of water quality purification measure is greatly dependent on the tidal exchange between the lagoon and the sea area. In addition, flow in a lagoon area is highly modified by topographical condition at a tidal inlet (e.g., Fukuoka et al., 2002) Therefore, it is important to understand the relationship between hydrodynamics in a tidal inlet and topographical condition.

The Nagatsura-ura Lagoon and Oppa Bay are connected by shallow tidal inlet, and its water depth may greatly affect hydrodynamics and water environment in the lagoon. Recently, this narrow channel is getting shallower due to predominant sediment intrusion by waves. Thus, it is estimated that the water quality has deteriorated in the bay due to weakened tidal exchange. However, because of limited number of topographical survey data in the channel, quantitative discussion is hardly possible between the inlet morphological change and water quality degradation.

In this study, time variation of water level in the lagoon in response to tide is investigated through spectral analysis to quantify the role of water depth in the hydrodynamic process. Furthermore, the relationship between the inlet water depth and salinity concentration intruding into the lagoon is examined through 3-D numerical simulation.

\section{STUDY AREA AND FIELD DATA}

\section{Nagatsura-ura Lagoon}

The Nagatsura-ura Lagoon is located in the north-east of the main land of Japan. A map of the study area is shown in Figure 1. Area of the Nagatsura-ura Lagoon is $1.4 \mathrm{~km}^{2}$, with the perimeter length of $8 \mathrm{~km}$. Because of small catchment area, the freshwater discharge is negligibly small as compared with tidal discharge through the inlet.

The water level has been measured every five minutes in the Nagatsura-ura lagoon by an automated water level gauge deployed at St.1 and St.2 in Figure 1. Water level observation has been stared in October, 2002. Furthermore, the tidal level data at Ayukawa Port was downloaded from the web site of the Japan Meteorological Agency. Time interval of tidal level observation is every $1 \mathrm{hr}$. Hence the tidal elevation was interpolated every five minutes to be compared with the water level variation measured in the lagoon. The distance between Ayukawa Port and the Nagatsura-ura Lagoon is about $30 \mathrm{~km}$.

In Figure 1, St.A is a point where salinity concentration is calculated using 3D numerical simulation as described later.

\footnotetext{
${ }^{1}$ Department of Civil Engineering, Kagawa National College of Technology, 355 Chokushi-choe, Takamatsu 7618058, Japan

${ }^{2}$ Department of Civil Engineering, Tohoku University, 6-6-06 Aoba, Sendai 980-8579, Japan
} 


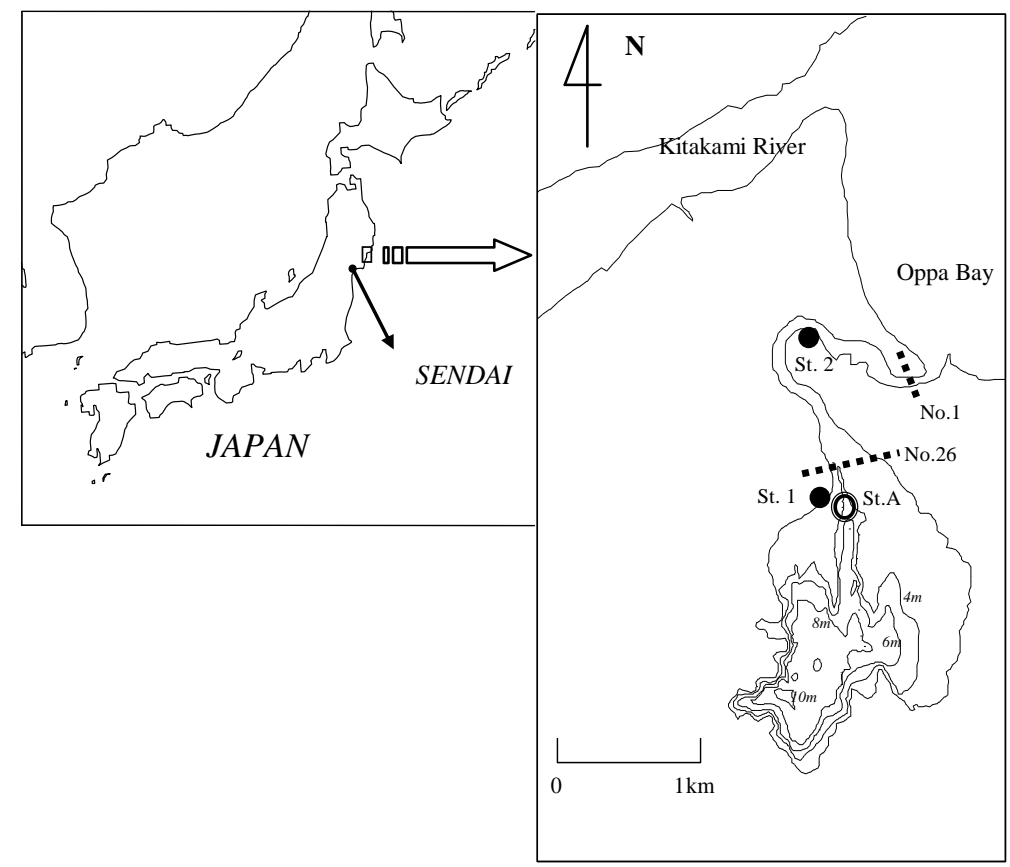

Figure 1. The study area of Nagatsura-ura lagoon

\section{Measured water level in the lagoon}

An example of water level variation measured at St.1 is shown in Figure 2, along with the tidal elevation at Ayukawa Port. Although the water level in the lagoon shows time-variation in response to tide, there is a distinct difference between these two water levels. One of the important features is that the water level in the lagoon cannot be lowered during low tide as compared with tide, due to shallow water depth along the tidal inlet. This indicates that the tidal prism, which represents water volume exchanges between the lagoon and the sea, is not so much as that estimated from tidal variation in the sea.

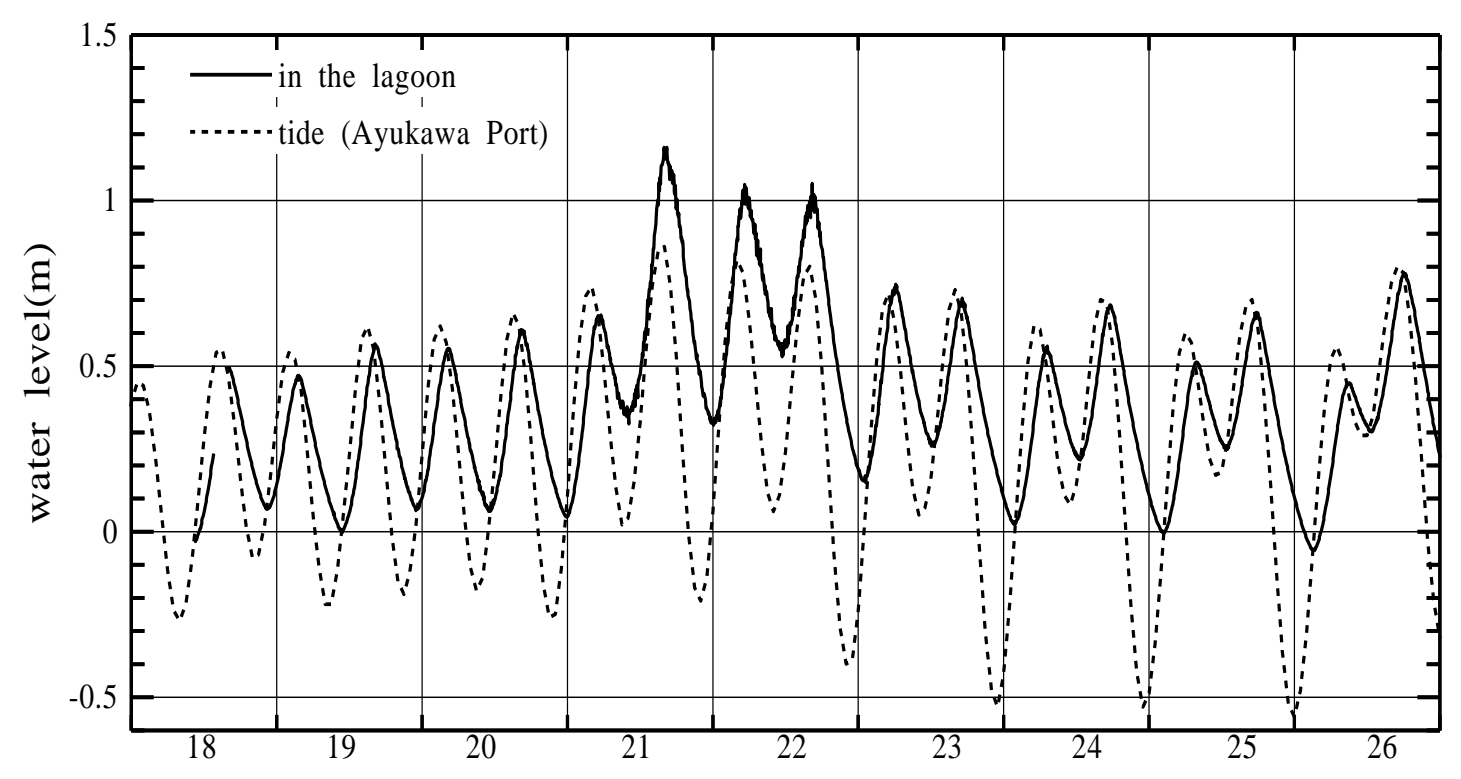

Figure 2. Water level data (Oct., Nov., 2002) 


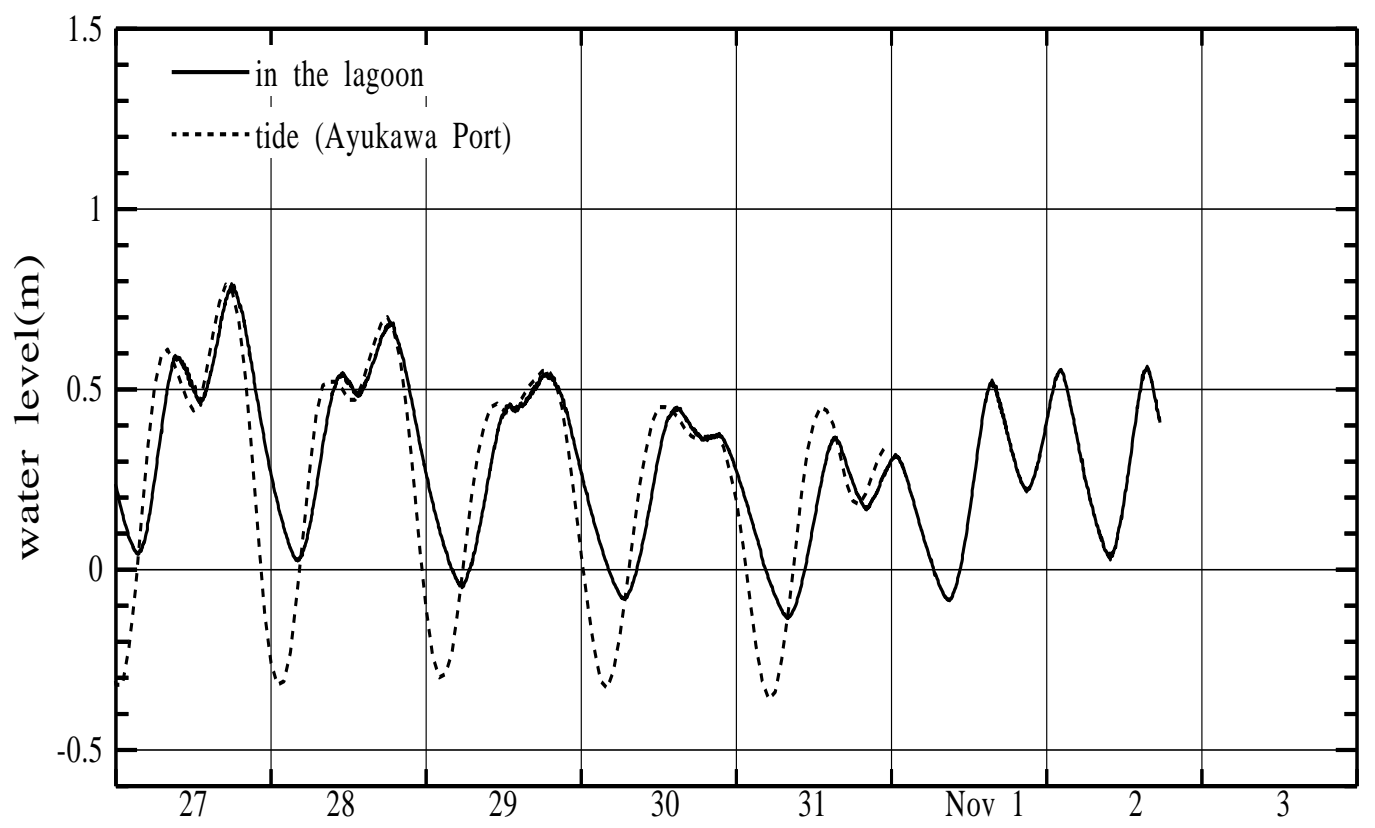

Figure 2. Water level data (Oct., Nov., 2002) (Cont'd)

Another interesting feature can be characterized by water level rise in the lagoon above tidal level on October 21 and 22. In particular, the water level rise above the tide attained to about $30 \mathrm{~cm}$ on October 21. This is wave set-up, induced by wave breaking under storm condition. Similar phenomenon has already been reported at river entrances in Japan, such as Nanakita River mouth (Tanaka et al., 2000), Natsui River mouth (Tanaka et al., 2000), Shiribetsu River mouth (Tanaka and Lee, 2003), and Nagase River mouth (Narita et al., 2002). Water level rise due to wave set-up causes increase in tidal prism beyond supposed one due to tidal variation, which can be frequent impacts on lagoon environment.

\section{Topographic data}

The change in cross-section at the Nagatsura-ura Lagoon has been measured along 26 sections by the Ministry of Land, Infrastructure and Transport in July, 2004 (see Fig.1). Two examples of measured cross-section are shown in Figures 3 and 4. Among 26 measurements, their cross-sectional shape greatly differs as seen in these figures. However, the flow in the shallower portion seen in Figure 4 is extremely stagnant because the water depth is less than $0.5 \mathrm{~m}$. Therefore, it is assumed that the shallow area can be neglected in the numerical analysis described in the following section.

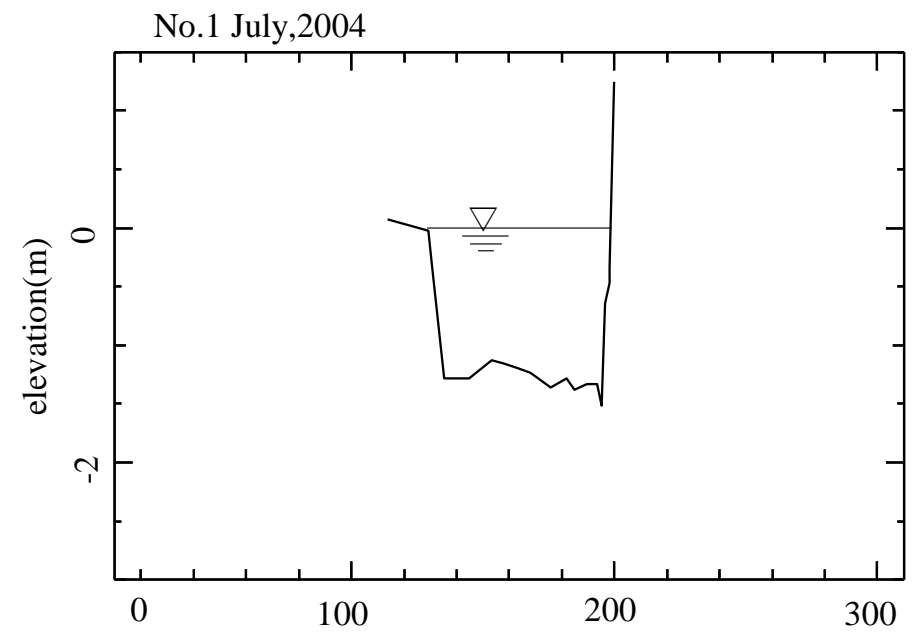

Figure 3. Measured cross-section (No.1)

distance (m) 


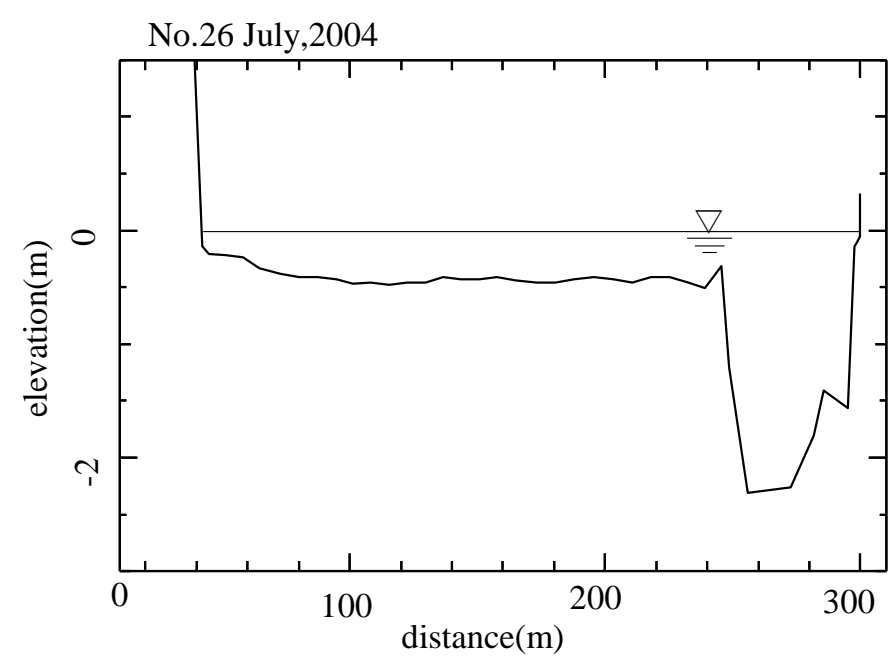

Figure 4. Measured cross-section (No.26)

In addition, the cross-sectional shape of the tidal inlet is approximated by rectangular. The averaged water depth thus obtained is $h=0.74 \mathrm{~m}$ below the mean sea level.

\section{RELATIONSHIP BETWEEN INLET WATER DEPTH AND SPECTRUM}

\section{Numerical analysis method}

The governing equations in the present numerical analysis are given by Eqs.(1) and (2), the equations of motion and continuity, respectively (Keulegan, 1967).

$$
\begin{aligned}
& \eta_{o}-\eta_{R}=\left(K_{e n}+K_{e x}+\frac{2 g n^{2} L}{R^{4 / 3}}\right) \frac{|U| U}{2 g} \\
& U=\frac{\boldsymbol{A}_{R}}{\boldsymbol{A}_{\boldsymbol{C}}} \frac{\boldsymbol{d} \eta_{R}}{\boldsymbol{d} \boldsymbol{t}}
\end{aligned}
$$

where $\eta_{O}$ is the tidal elevation, $\eta_{R}$ is the water level in the lagoon, $K_{e n}$ is the entrance loss coefficient, $K_{e x}$ is the exit loss coefficient, $n$ is Manning's coefficient of roughness, $L$ is the channel length, $R$ is the hydraulic radius, $U$ is the velocity, $A_{R}$ is the tidal area, and $A_{c} i s$ the cross-sectional area of the tidal inelt. Furthermore, the shape of the inlet cross-section is assumed to be rectangular.

Parameters in Eqs.(1) and (2) other than the water depth are regarded as known quantities. Thus, the inlet depth $h$ is assumed, and Eqs.(1) and (2) are solved numerically using the Runge-Kutta method. Consequently, we obtain the calculated water level in the lagoon $\eta_{R}$. Then, an estimation of water depth can be made by finding a depth which minimizes the error between the calculated and measured spectrum.

\section{Power spectral analysis of water level variation}

In the numerical analysis using Eqs.(1) and (2), the water depth is varied from $h=0.5 \mathrm{~m}$ to $2.5 \mathrm{~m}$, and the corresponding spectrum is shown in Figure 5. In addition, the power spectrum from the measured water level is also depicted by the solid line in this figure. It is seen that semidiurnal and diurnal components are most predominant both in the measurement and numerical calculation. With the increase of the assumed water depth, the spectrum is almost similar to that of tidal motion. With the decrease of the water depth, the short period component becomes more predominant due to the bottom friction term with quadratic form in the governing equation. From this figure, the water depth is estimated to be $h=0.7 \mathrm{~m}$. 


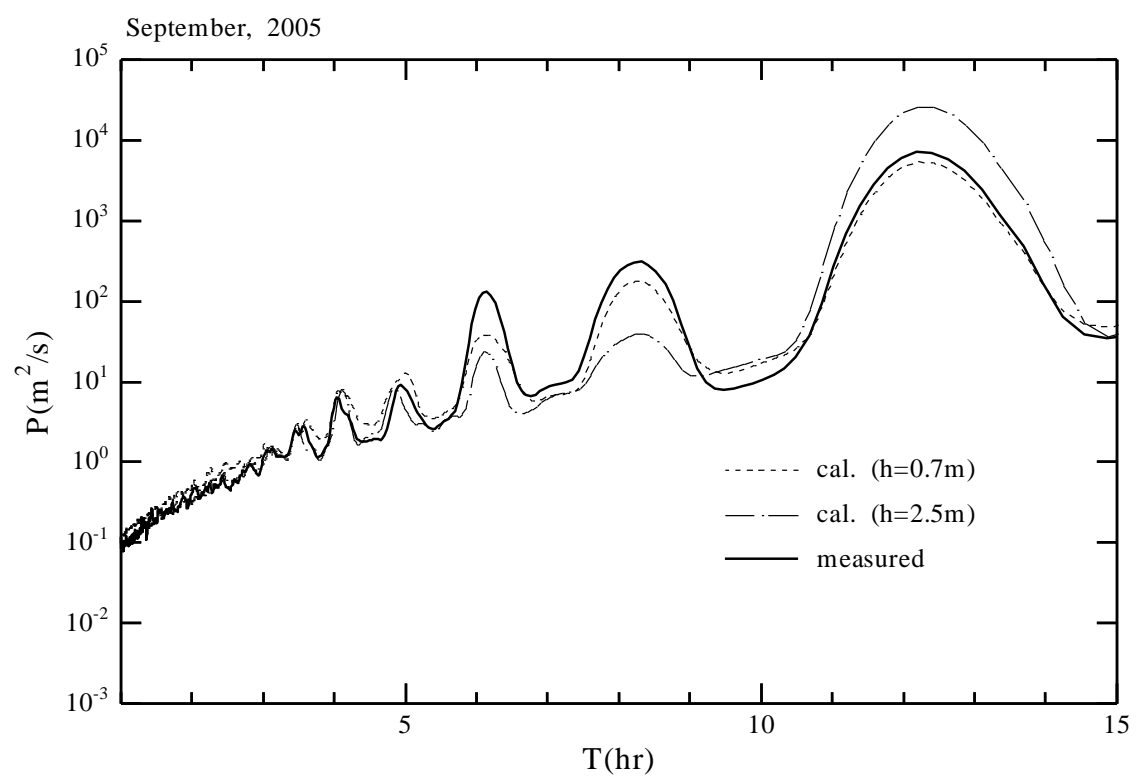

Figure 5. Power spectrum of water level

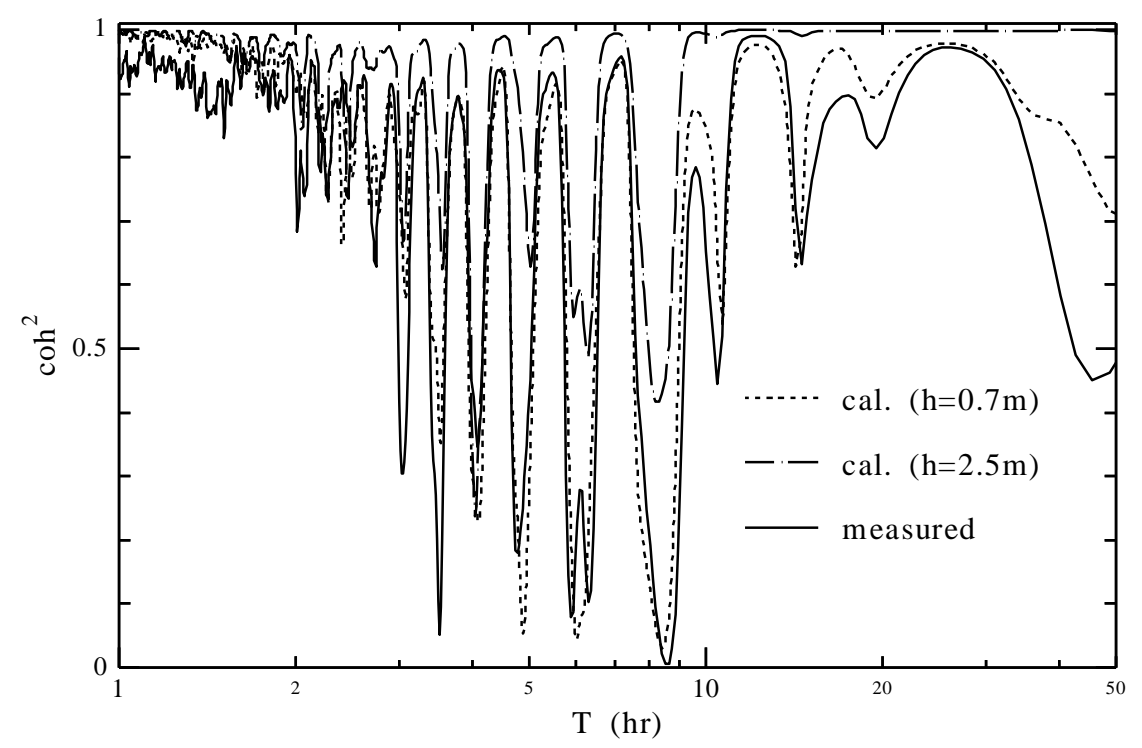

Figure 6. Coherence of water level and tidal level

\section{Cross-spectral analysis of water level variation}

The cross-spectrum is calculated to uncover the correlation between tidal level and the water level in the lagoon. The coherence is obtained from calculated and measured water level, and is shown in Figure 6. In comparison with cases of $h=0.7 \mathrm{~m}$ and $2.5 \mathrm{~m}$, the result from the assumption of $h=0.7 \mathrm{~m}$ gives close agreement with the measurement. In the computation with the depth of $2.5 \mathrm{~m}$, the coherence is almost equal to 1.0, indicating high correlation between these two due to less magnitude of the friction term in the governing equation.

Next, the phase is calculated from estimated water level as seen in Figure 7. It is again confirmed that the measured phase shows close agreement with the estimation with the depth of $h=0.7 \mathrm{~m}$.

In conclusion, spectral analysis is very useful for estimating water depth at the tidal inlet. In general, frequent surveying of tidal inlet water depth is costly. The present estimation method enables inexpensive monitoring of water depth using time-variation of measured water level. 


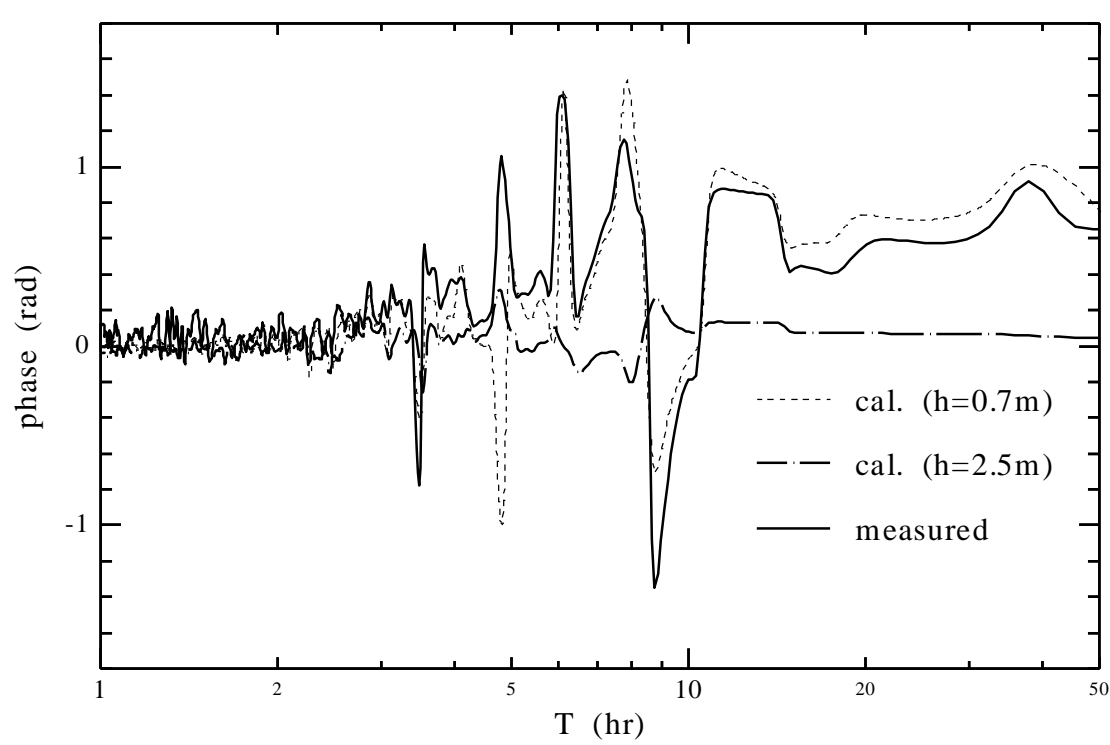

Figure 7. Phase of water level in bay and sea level

\section{RELATIONSHIP BETWEEN INLET WATER DEPTH AND SALINITY CONCENTRATION}

\section{Numerical model}

The hydrodynamic model adopted here is the one based on the hydrostatic pressure approximation and the boussinesq approximation, and fixed layer divisions in vertical discretization. This model basically follows the procedure introduced by Sato et al. (1993) with addition of baroclinic term to take into account the effect of density gradient. A set of governing equations is required to compute four unknowns, three velocity components and water level. The momentum equations are

$$
\begin{aligned}
& \frac{\partial u}{\partial t}+u \frac{\partial u}{\partial x}+v \frac{\partial u}{\partial y}+w \frac{\partial u}{\partial z}=-g \frac{\partial \eta}{\partial x}-\frac{g}{\rho_{0}} \frac{\partial}{\partial x} \int_{z}^{\eta} \rho^{\prime} d z+v_{h}\left(\frac{\partial^{2} u}{\partial x^{2}}+\frac{\partial^{2} u}{\partial y^{2}}\right)+\frac{\partial}{\partial z}\left(v_{v} \frac{\partial u}{\partial z}\right) \\
& \frac{\partial v}{\partial t}+u \frac{\partial v}{\partial x}+v \frac{\partial v}{\partial y}+w \frac{\partial v}{\partial z}=-g \frac{\partial \eta}{\partial y}-\frac{g}{\rho_{0}} \frac{\partial}{\partial y} \int_{z}^{\eta} \rho^{\prime} d z+v_{h}\left(\frac{\partial^{2} v}{\partial x^{2}}+\frac{\partial^{2} v}{\partial y^{2}}\right)+\frac{\partial}{\partial z}\left(v_{v} \frac{\partial v}{\partial z}\right)
\end{aligned}
$$

and the continuity equation is

$$
\frac{\partial u}{\partial x}+\frac{\partial v}{\partial y}+\frac{\partial w}{\partial z}=0
$$

Here, $(u, v, w)$ is flow velocity in the direction of $(x, y, z), \eta$ is the height of free water surface, $g$ is the gravity, $\rho_{0}$ is a constant reference density, $\rho^{\prime}(x, y, z, t)$ is the local variation from the reference density, $v_{h}$ and $v_{v}$ are the eddy viscosity coefficients in horizontal and vertical respectively. Calculation of $\eta$ is based on depth integration of Eq.(5) with kinematic boundary condition at the free surface to obtain

$$
\frac{\partial \eta}{\partial t}+\frac{\partial}{\partial x}\left[\int_{-H}^{\eta} u d z\right]+\frac{\partial}{\partial y}\left[\int_{-H}^{\eta} v d z\right]=0
$$

where $H$ is depth of bottom boundary measured from undisturbed free water surface.

Density is calculated by using water temperature and salinity resulted from solution of the associated advection diffusion equations

$$
\begin{aligned}
& \frac{\partial T}{\partial t}+u \frac{\partial T}{\partial x}+v \frac{\partial T}{\partial y}+w \frac{\partial T}{\partial z}=\frac{\partial}{\partial x}\left(\varepsilon_{h} \frac{\partial T}{\partial x}\right)+\frac{\partial}{\partial y}\left(\varepsilon_{h} \frac{\partial T}{\partial y}\right)+\frac{\partial}{\partial z}\left(\varepsilon_{z} \frac{\partial T}{\partial z}\right)+\frac{1}{\rho_{0} C_{p}} \frac{d q}{d z} \\
& \frac{\partial S}{\partial t}+u \frac{\partial S}{\partial x}+v \frac{\partial S}{\partial y}+w \frac{\partial S}{\partial z}=\frac{\partial}{\partial x}\left(\varepsilon_{h} \frac{\partial S}{\partial x}\right)+\frac{\partial}{\partial y}\left(\varepsilon_{h} \frac{\partial S}{\partial y}\right)+\frac{\partial}{\partial z}\left(\varepsilon_{z} \frac{\partial S}{\partial z}\right)
\end{aligned}
$$

where $T$ is water temperature, $S$ is salinity, $q$ is heat flux, $C_{p}$ is specific heat of water, $\varepsilon_{h}$ and $\varepsilon_{v}$ are the eddy viscosity coefficients in horizontal and vertical respectively. Parameterization of turbulence uses the QETE (quasi-equilibrium turbulent energy) model (Galperin et al., 1988), which is still in the family of Mellor Yamada turbulence closure (Mellor and Yamada, 1982). 
The above governing equations are solved numerically by using a finite difference method. Very fine grid is applied in the horizontal with uniform size of $20 \mathrm{~m}$ x $20 \mathrm{~m}$. Vertical domain of computation is divided into 40 layers. The uppermost layer is set to 1 meter of thickness and the rest of the layers are set to $0.25 \mathrm{~m}$ of thickness. More detail of computation method can be found elsewhere (Purwanto et al., 2007).

The inlet water depth is varied from $1 \mathrm{~m}$ to $4.5 \mathrm{~m}$ with $0.5 \mathrm{~m}$ interval to investigate the influence of the depth on salinity concentration into the lagoon.

\section{Results and discussions}

Calculated results of water levels variation in the tidal inlet and salinity concentration at the bottom of St.A (see Fig.1) are shown in Figure 8. It is seen that during higher hide tide, the salinity concentration shows less dependence on the water depth. During low tide, however, distinct difference of the salinity can be observed, especially during lower low tide.

Figure 9 shows the longitudinal variation of the inflowing velocity and salinity concentration. Here, three cases are illustrated for shallow water depth $(h=1 \mathrm{~m})$, intermediate water depth $(h=2.5 \mathrm{~m})$, and deep water depth $(h=4.5 \mathrm{~m})$. It is clearly seen that the deeper channel allows inflowing of higher salinity concentration. Distinct salinity stratification can be observed near the entrance, and subsequently its vertical profile gradually gets uniformly distributed due to turbulence as it flows farther upstream along the tidal inlet.

The relationship between inflowing salinity concentration and the inlet water depth is shown in Figure 10. It is seen that the relationship can be approximated by the following exponential equation.

$$
S_{\text {inf low }}=33.5-6.98 \exp \left(-0.136 h_{\text {channel }}\right)
$$

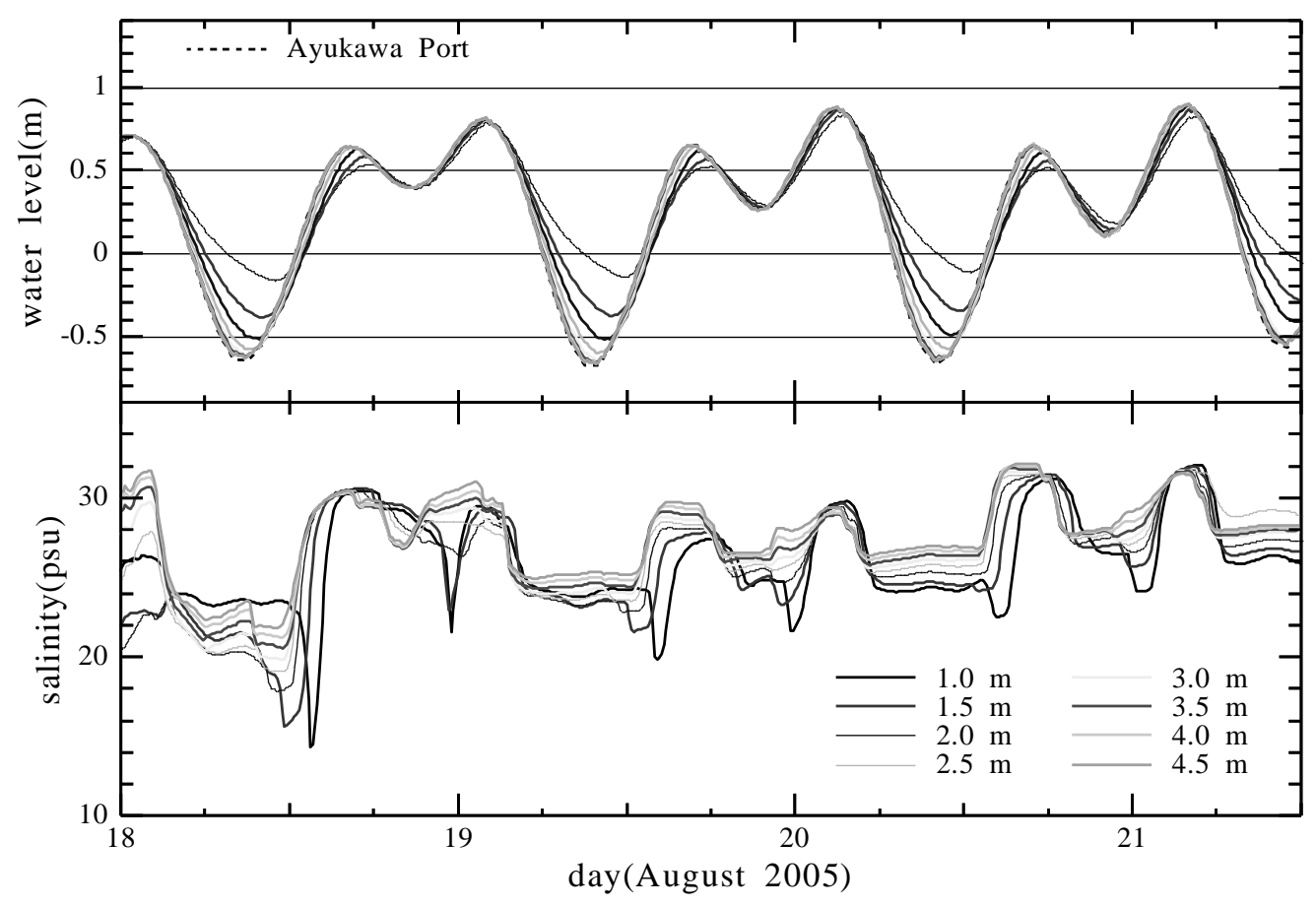

Figure 8. Calculated salinity at St.A 

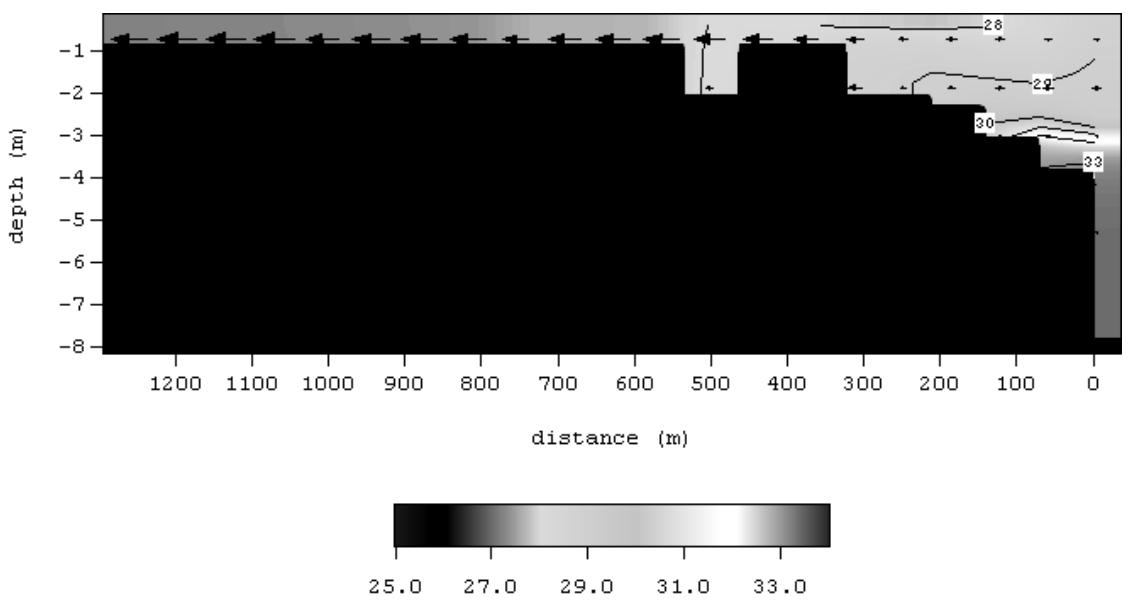

salinity (psu

(a) $h=1.0 \mathrm{~m}$
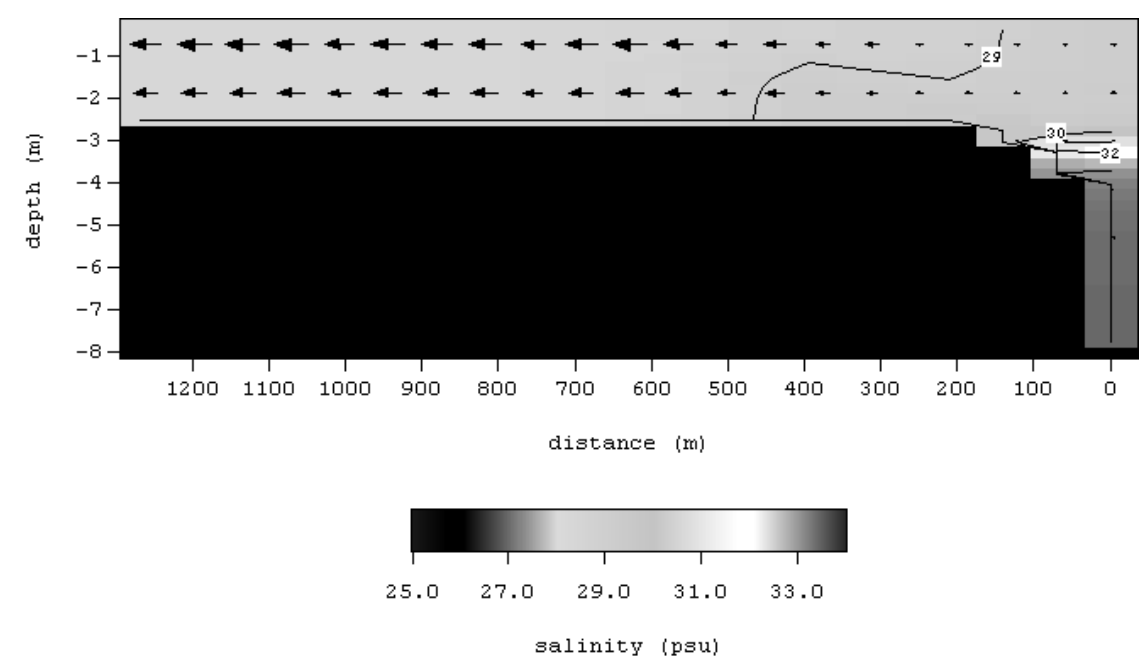

(b) $h=2.5 \mathrm{~m}$

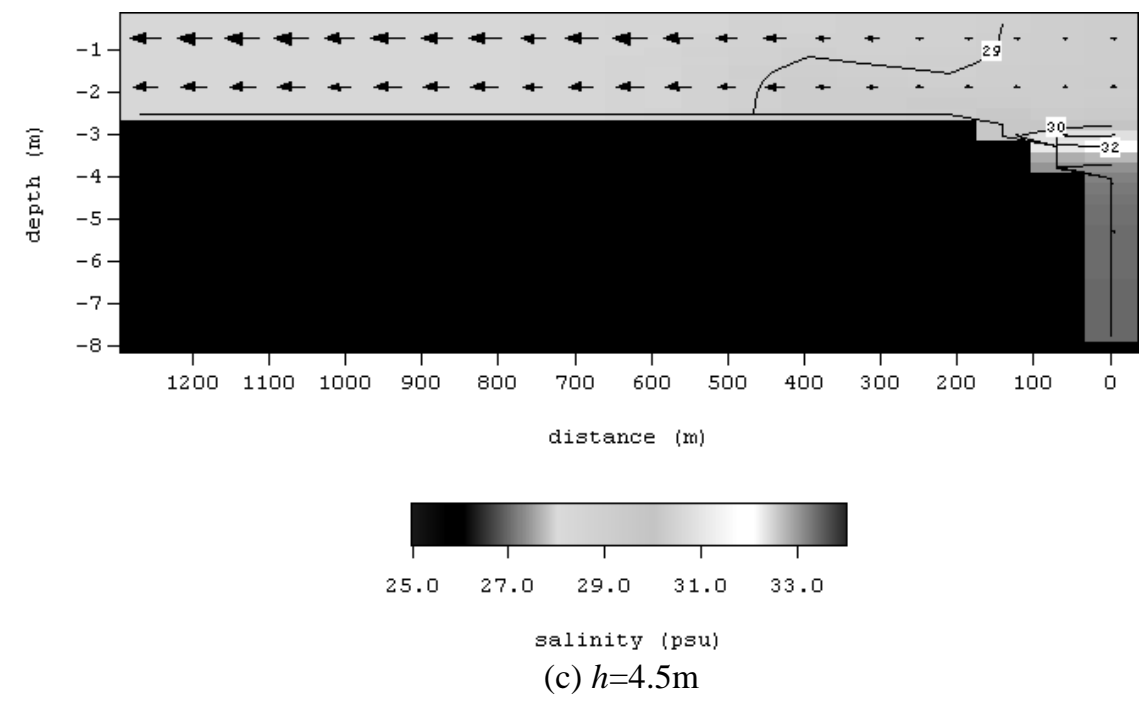

Figure 9. Distribution of velocity vector and salinity 


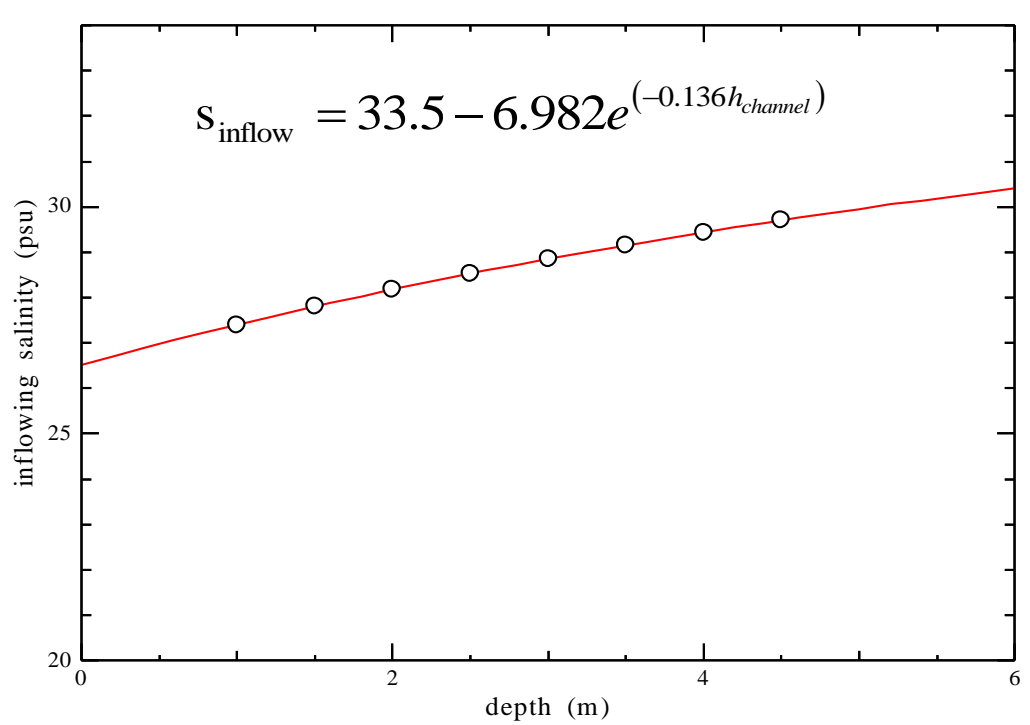

Figure 10. Relationship between inflowing salinity and water depth

\section{CONCLUSIONS}

In this study, characteristics of water level and flow and resulting salinity intrusion at the Nagatsura-ura Lagoon have been examined by measured data and numerical calculation. The following conclusions are drawn in this study.

1. Spectral analysis of the water level variation in the lagoon revealed that short period component is generated by the effect of bottom friction acting in the tidal inlet of the Nagatsura-ura Lagoon.

2. The inlet depth of the Nagatsura-ura Lagoon is estimated by comparing measured and estimated spectrum. This estimation method can be applied to other river mouths also, and this will be practically useful for monitoring of river mouth depth.

3. 3-D numerical simulation shows that salinity concentration inflowing into the Nagatsura-ura Lagoon is highly dependent on the inlet water depth. According to the numerical simulation, intruding salinity concentration increases exponentially with the increase of the inlet water depth.

\section{ACKNOWLEDGMENTS}

The authors would like to express their grateful thanks to Kitakamigawa-karyu River Office, Tohoku Regional Development Bureau, Ministry of Land, Infrastructure and Transport, Japan for their kind offer of the field data. This research was partially supported by Grant-in-Aid for Scientific Research (B) (No.21360230) from JSPS, Japan.

\section{REFERENCES}

Fukuoka, S., Matsushita, T., Miura, S., Kurokawa, T., Funabashi, S. and Nakamura, M. 2002. On salinity variation connected brackish lake, Annual Journal of Hydraulic Engineering, 46, 899904.(in Japanese)

Galperin, B., Kantha, L. H., Hassid, S., and Rosati, A. 1988. A quasi-equilibrium turbulent energy model for geophysical flows, Journal of the Atmospheric Sciences, 45, 55-62.

Keulegan, G.H. 1967. Tidal Flow in Entrances, U.S. Army Corps of Engineers, Committee on Tidal Hydraulics, Technical Bulletin, 14, 102p.

Mellor, G. L., and Yamada, T. 1982. Development of a turbulence closure model for geophysical fluid problems, Rev. Geophys. Space Phys., 20, 851-875.

Narita, M., Ishikawa, T. and Takahashi, A. 2002. Characteristics of the river mouth on the Takase River, Proceedings of Coastal Engineering, JSCE, 49, pp.526-530.(in Japanese) 
Purwanto, B.S., Tanaka, H., Kanayama, S., Takasaki, M. and Yamaji, H. 2007. Mid-layer intrusion simulation in Nagatsura-ura Lagoon, Proceedings of 32nd IAHR Congress, 2007.(CD-ROM)

Sato, K., Matsuoka, M., and Kazumitsu, K., 1993. Efficient calculation method of 3-D tidal current. Proceedings of Coastal Engineering, JSCE, 40, 221-225.(in Japanese).

Tanaka, H., Nagabayashi, H. and Yamauchi, K. 2000. Observation of wave set-up height in a river mouth, Proceedings of 27th International Conference on Coastal Engineering, 3458-3471.

Tanaka, H. and Lee, H. S. 2003. Influence of jetty construction on morphology and wave set-up at a river mouth, Coastal Engineering Journal, 45(4), 659-683. 